\section{Commentary: Restructuring the education of cardiac and thoracic surgeons}

\author{
Travis C. Geraci, MD, ${ }^{\mathrm{a}}$ and Thomas Ng, MD ${ }^{\mathrm{b}}$
}

In a comprehensive review of strategies to optimize cardiothoracic surgical training, $\operatorname{Dr~Lin}^{1}$ suggests the implementation of competency-based assessments, coaching, simulation, and internet-based applications. Certainly, we should strive for more effective and efficient educational modalities, but is this enough? Given the expansive knowledge, judgment, and technical mastery required to achieve quality outcomes in cardiothoracic surgery, bolder approaches to educational reform are needed. Should we further separate cardiac and thoracic surgical training? And if so, to what degree? Is a complete division inevitable?

With the evolution of the integrated 6-year (I-6) pathway-a model that may poorly prepare thoracic surgeons for gastrointestinal and foregut surgery ${ }^{2}$-we have already initiated the separation. The I- 6 model provides a specialty-centered framework for a more focused, relevant training experience. Many subspecialties (plastic surgery, orthopedics, neurosurgery) have successfully shed generalized training for a sleeker subspecialty experience under the mentorship of their own departments. The calculus of educational ownership is simple: There's a lot to learn, some of it seems unnecessary, and there's not enough time to do it all. Assuredly, there are intellectual and operative benefits to training in both specialties, but these are achieved at the expense of a diluted educational experience and resident burnout. Our current system produces a significant number of surgeons who are not comfortable performing the core procedures of the opposite "track" within a few years of graduation (Figure 1).

The operative breadth and complexity of cardiothoracic surgery_including coronary, valve, and aortic surgery, heart

From the ${ }^{\mathrm{a} D e p a r t m e n t}$ of Cardiothoracic Surgery, New York University, Langone Health, New York, NY; and ${ }^{\mathrm{b}}$ Division of Thoracic Surgery, University of Tennessee Health Science Center College of Medicine, Memphis, Tenn.

Disclosures: The authors reported no conflicts of interest.

The Journal policy requires editors and reviewers to disclose conflicts of interest and to decline handling or reviewing manuscripts for which they may have a conflict of interest. The editors and reviewers of this article have no conflicts of interest.

Received for publication Sept 20, 2020; revisions received Sept 20, 2020; accepted for publication Sept 23, 2020; available ahead of print Sept 30, 2020.

Address for reprints: Thomas Ng, MD, 1325 Eastmoreland Ave, Suite 460, Memphis, TN 38104 (E-mail: tng4@uthsc.edu).

J Thorac Cardiovasc Surg 2021;162:510-1

$0022-5223 / \$ 36.00$

Copyright (c) 2020 by The American Association for Thoracic Surgery

https://doi.org/10.1016/j.jtcvs.2020.09.085

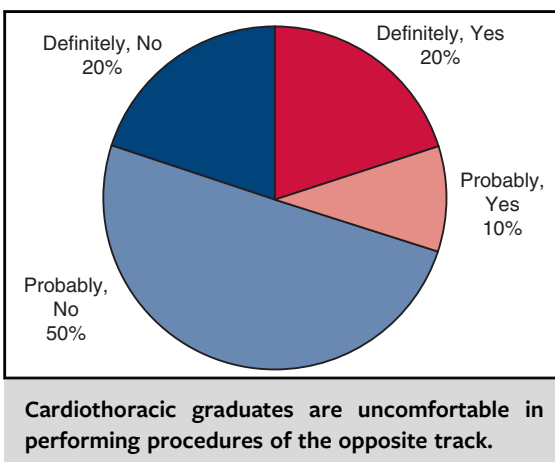

CENTRAL MESSAGE

The growth of information and techniques in cardiac and thoracic surgery has exceeded a threshold in which combined cardiothoracic training is no longer the optimal educational paradigm.

failure, congenital cardiac surgery, heart and lung transplantation, pulmonary resection, mediastinal, trachea, and esophageal surgery-have surpassed a threshold of traditional 2-year, or even 3-year, fellowships. The prevalence of super-fellowship positions reflects the specialty's magnitude. It is hubristic to trust that surgeons will achieve adequate case volumes to maintain proficiency, or even mandated minimum volumes, for all these operations. Critically, patient outcomes are correlated to surgeon volume, often regardless of the case volume of the hospital where the operations are performed. ${ }^{3}$ Furthermore, attempting to sustain the entirety of cardiothoracic surgery distracts from dominating emerging facets of the field, such as hybrid/transcatheter cardiac interventions or advanced bronchoscopic and endoscopic treatment modalities. Do cardiac surgeons favor referring patients for a transcatheter valve but remain certified to perform a lobectomy?

The educational system in Canada, which separated the training of cardiac and thoracic surgeons in 1994, serves as a model for restructuring. ${ }^{4,5}$ For cardiac surgery training, the I-6 pathway continues to be successful; however, for thoracic surgery, the I-6 pathway was trialed and "abandoned because of a lack of suitable applicants and insufficient training in general surgery for applicants to be competent in foregut surgery." 5 For example, if a resected esophagus requires colon interposition for reconstruction, 


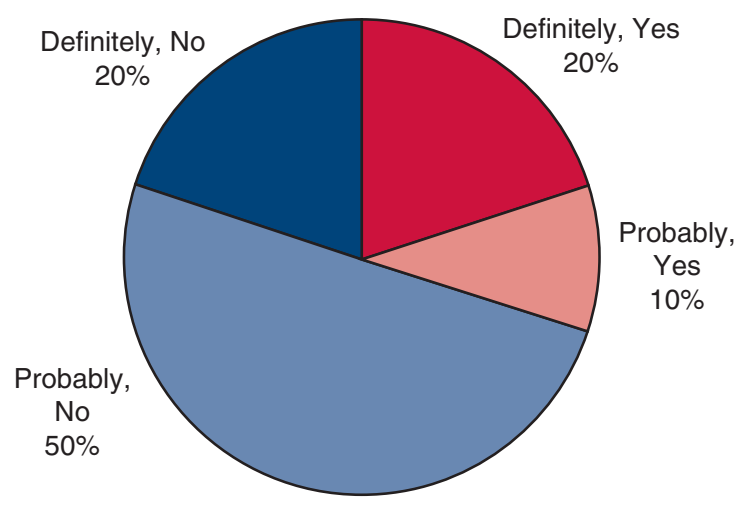

FIGURE 1. We surveyed 20 recent cardiothoracic graduates with a mean time since graduation of 18.5 months, asking whether they would be comfortable performing a minimally invasive lobectomy if they identified as a "cardiac surgeon" or coronary artery bypass grafting if they identified as a "thoracic surgeon." The majority were uncomfortable.

it would make sense that a "full training in general surgery is essential." ${ }^{2}$ In 2002, thoracic surgery programs in Canada reverted back to requiring the completion of general surgery before entering into the 2 years of thoracic training.

Although the specialty would benefit from supporting career pathways for surgeon-educators and the refinement of teaching strategies as Dr Lin expounds, ${ }^{1}$ these efforts treat the symptoms of educational overload, not the disease itself. More radical change is needed. Restructuring case requirements for cardiac and thoracic surgery is an intuitive starting point: maximize exposure to career-focused operations and reduce or eliminate requirements of least utility, for example, esophageal and foregut surgery for cardiac residents and congenital heart and hybrid/transcatheter cases for thoracic residents. This raises the question, Is cardiothoracic surgery training even relevant with this asymptotic winnowing of procedural overlap?
The separation of cardiac and thoracic boards may be an inevitable consequence of a burgeoning field under escalating oversight and exacting scrutiny of clinical outcomes. We recognize that, beyond education, there are disadvantages to separating the specialty, including (but not limited to) dissolving political leverage and reduced surgical coverage for rural or underserved regions. With approximately one-third of surgeons performing both cardiac and thoracic surgery, ${ }^{6}$ there remains a need for a traditional cardiothoracic surgeon. Would a third track focused on core operations help produce these surgeons? Additional fracturing of cardiothoracic training may further complicate a system already contending with multiple tracks and pathways.

Suggesting further, or even complete, separation of cardiothoracic surgery may seem overly radical. Division, however, is not a novel concept and has been considered by leaders in the field for decades. ${ }^{6}$ With the continued expansion of both cardiac and thoracic surgery, it is increasingly difficult to master it all. Bold educational reforms are needed.

\section{References}

1. Lin J. Evolution of the thoracic surgeon educator: incorporating education science into our DNA. J Thorac Cardiovasc Surg. 2021;162:503-9.

2. Darling GE, Maziak DE, Clifton JC, Finely RJ. The practice of thoracic surgery in Canada. Can J Surg. 2004;47:438-45.

3. Birkmeyer JD, Stukel TA, Siewers AE, Goodney PP, Wennberg DE, Lucas FL. Surgeon volume and operative mortality in the United States. $N$ Engl J Med. 2003;349:2117-27.

4. Noly PE, Rubens FD, Ouzounian M, Quantz M, Shao-Hua W, Pelletier M, et al Cardiac surgery training in Canada: current state and future perspectives. J Thorac Cardiovasc Surg. 2017;154:998-1005.

5. Grondin SC, Schieman C. Thoracic surgery education in Canada. J Thorac Cardiovasc Surg. 2017;153:493-7.

6. Wood DE. Cardiothoracic surgery: a specialty divided or as one. J Thorac Cardiovasc Surg. 2009;137:1-9. 